\title{
Selected Trace Elements in Domestic Water Boreholes and Their Implications on Human Health, in Huruma Estate, Eldoret Municipality, Uasin-Gishu County, Kenya
}

\author{
Taratisio Ndwiga
}

Department of Environmental Health, School of Public Health, Moi University, Eldoret, Kenya.

Email: taratisiondwiga@yahoo.com

Received November $8^{\text {th }}$, 2013; revised December $11^{\text {th }}, 2013$; accepted January $7^{\text {th }}, 2014$

Copyright (C) 2014 Taratisio Ndwiga. This is an open access article distributed under the Creative Commons Attribution License, which permits unrestricted use, distribution, and reproduction in any medium, provided the original work is properly cited. In accordance of the Creative Commons Attribution License all Copyrights (c) 2014 are reserved for SCIRP and the owner of the intellectual property Taratisio Ndwiga. All Copyright (C) 2014 are guarded by law and by SCIRP as a guardian.

\section{ABSTRACT}

Trace elements constitute less than $1 \%$ of the rocks in the crust (Stumm and Morgan, 1991). In the human body, they constitute less than $100 \mathrm{mg} / \mathrm{kg}(\mathbf{0 . 0 1 \%})$. These elements are released to the environment naturally by weathering and volcanic activities (Flint and skinner, 1997). It has been observed that trace elements are greatly absorbed and retained in the body when in liquid diet. This phenomenon also influences the risk to human health, especially of infants and children whose immature digestive system further promote absorption of toxic heavy metals. The study was based on the analysis of domestic borehole water supplies in Huruma estate of Eldoret Municipality for selected trace elements and their implications on human health. The boreholes were systematically selected for sampling points and trace elements, $\mathrm{Cr}, \mathrm{Cu}$ and Se analyzed using AAS. Statistical analysis for mean, standard deviation and confidence interval limits was done using SPSS. The statistical t-test was used to test for significance differences at $(p=0.05)$. The graphs were drawn using the Microsoft Excel package. The resulting data obtained from analysis were compared with WHO data for drinking water. In the study, the mean values of the following parameters were as follows: Chromium $17.9 \mu \mathrm{g} / \mathrm{L}$, Copper $563 \mu \mathrm{g} / \mathrm{L}$ and Selenium 22.7 $\mu \mathrm{g} / \mathrm{L}$. There was a significant difference at $5 \%$ level of significance $(p=0.000)$ in all the parameter values among the sampling points in Huruma estate. The above mean values were far below the WHO recommended limits for drinking water. It was concluded that the borehole water from Huruma was fit for drinking and therefore could not cause cancer and cardiovascular diseases. However, borehole water should be used if other water sources (tap water etc.) were not available. All the industries near Huruma estate should carefully analyze and regularly monitor their liquid waste effluents to ensure that no harmful discharges get into the soil.

\section{KEYWORDS}

Trace Elements; Human Health; Chronic Exposure; Borehole; Non-Communicable Disease

\section{Introduction}

Trace elements constitute less than $1 \%$ of the rocks in the crust [1]. In the human body, they constitute less than $100 \mathrm{mg} / \mathrm{kg}(0.01 \%)$. These elements are released to the environment naturally by weathering and volcanic activities [2]. It has been observed that trace elements are greatly absorbed and retained in the body when in liquid diet. This phenomenon also influences the risk to human health, especially of infants and children whose imma- ture digestive system further promote absorption of toxic heavy metals. Deficiencies, excesses or imbalances in the supply of trace of elements from water and dietary sources can be an important influence on animal and human health and susceptibility to diseases.

The concentration of trace elements in the environment is modified by a variety of natural processes and deliberate and accidental human activities. Certain trace element e.g. Selenium (Se) and Molybdenum (Mo) intrigue modern scientists because of the environmental 
consequence of their double-edged behavior. Depending on their concentration and chemical forms, they function as essential elements or potent toxicants to humans, livestock, plans, waterfowls and certain bacteria. Manganese (Mn), Chromium (Cr), Vanadium (V) and Copper $(\mathrm{Cu})$ are known to have beneficial effects on heart disease as illustrated in their high concentrations in the low death-rate areas of Georgia, America [3]. Therefore, the low-death-rate may be as a result of an abundance of beneficial trace elements.

In Kenya, non-communicable diseases, especially cardiovascular diseases and cancer are increasing rapidly. Hypertension accounts for the majority of the cardiovascular disorders in Kenya and in developing countries. Regrettably, the ability to deal with this emerging problem is being hindered by two major factors a paucity epidemiological data about incidence, prevalence and trends in disease occurrences and absence of adequate resource allocation locally and by the international community [4].

Incidences of cancer and cardiovascular diseases are on the increase with some forms associated with trace element concentration. The study conducted at MTRH by [5] shows that esophageal cancer is the $9^{\text {th }}$ most common cancer in the world, and the $5^{\text {th }}$ most common cancer in developing countries, with approximately 300,000 newly diagnosed patients every year. He reported that the cancer cases recorded at the Hospital, from Jan. to May 2001 showed that the cancer incidence was $2 \%$ per 100,000 per year. Kenyatta National Hospital recorded the overall country incidence at $67 \%$ per 100,000 per year over the same period.

Domestic water particularly in volcanic environments is usually associated with high concentration levels of elements. The concentration ranges for trace elements in domestic water supplies is usually unknown because routine analysis ignores this component. Trace elements are further more toxic than other pollutants when they occur outside their recommended ranges and are greatly absorbed and retained in the body when taken in liquid form. The above scenario merits an investigation to characterize the domestic water supplies in terms of selected trace elements and find out their implication on human health.

Eldoret Municipality in Rift Valley Province is associated with volcanic activities that are a major source of trace elements. Water is a basic requirement for life and is extensively used in everyday life. However, if contaminated it has a capacity to transmit many disease. Furthermore, water is a major source of trace elements in human diet yet most reports on water analysis give only the concentrations of major elements that are recognized to affect the quality of water for domestic, agricultural and industrial uses.

The findings will contribute to knowledge in the quality of domestic water boreholes in Huruma estate in Eldoret Municipality in terms of the selected trace elements. Future decision on the necessary water treatment processes could be based on the findings and therefore lead to improvement in water quality and hence human health. The objective was to determine the level of $\mathrm{Cr}$, $\mathrm{Cu}$ and $\mathrm{Se}$ in domestic water supplies (boreholes) in $\mathrm{Hu}-$ ruma, Eldoret Municipality and determine the suitability of water for drinking.

Chronic exposure of chromium in man causes cancer of the respiratory tract and skin eczema. It also causes renal tubular necrosis. The lethal oral dose in human adults is $50-70 \mathrm{mg}$ of soluble chromates per kg body weight. At this level of ingestion, chromium causes poisoning of blood-forming organs. Chronic toxicity can be observed in several other mammalian species, with hexavelant chromium in concentrations of more than $5 \mathrm{mg} / \mathrm{L}$ [6].

It is possible for aquatic animals to accumulate high and ultimately lethal concentrations of heavy metals over long period from extremely low water concentrations. In USA the brown bullhead (Lctalurs nebulosus) has been shown to accumulate chromium to concentrations more than 2600 times that found in the stream water although this was still lower than the concentration in the stream sediment. In the IIIionis River the concentration of chromium in the muscles of omnivorous fish was found to be appreciably greater than that in the muscles of carnivorous fish although again the concentrations were less than that of the river sediment [7].

[8] explains that the average background concentrations of copper in air in rural areas range from 5 to 50 $\mathrm{ng} / \mathrm{m}^{3}$. Copper levels in fresh water of $1-20 \mu / \mathrm{L}$ are found in uncontaminated areas. The adverse health effects associated with copper include: anemia and bone abnormalities (due to copper deficiency), vomiting, diarrhea, headache, respiratory difficulty, liver and kidney failure, massive gastro-intestinal bleeding and death [8].

Selenium occurs naturally in a number of inorganic forms, including selenide, selenate and selenite. In soils, selenium most often occurs in soluble forms like selenate (analogous to sulfate), which are leached into rivers very easily by runoff. Natural sources of selenium include certain selenium-rich soils, and selenium that has been bioconcentrated by certain toxic plants such as locoweed. Anthropogenic sources of selenium include coal burning and mining and smelting of sulfide ores [9].

Although selenium is an essential trace element it is toxic if taken in excess. Exceeding the Tolerable Upper 
Intake Level of 400 micrograms per day can lead to selenosis [10]. Symptoms of selenosis include a garlic odour on the breath, gastrointestinal disorders, and hair loss, sloughing of nails, fatigue, irritability and neurological damage. Extreme cases of selenosis can result in cirrhosis of the liver, pulmonary edema and death [10].

There has been growing interest in trace elements in the environment because of their toxicity to plants and other living organisms. Trace metals have effects on human body organs especially the brain, kidney and the skin [11-13], analyzed 20 trace elements in samples from 60 boreholes located in the upper east and west regions of Ghana and observed that most trace elements concentrations were high as compared to their concentrations found in natural water. $\mathrm{Al}, \mathrm{Fe}, \mathrm{Mn}, \mathrm{Zn}, \mathrm{Sr}$, and $\mathrm{Ba}$ were excessively high in concentration in comparison with WHO guidelines.

[14] measures concentrations of heavy metals in the borehole at Dumasi in the Wassa West district of the Republic of Ghana. The concentrations of the metals in the ground water from Dumasi borehole show that resident adults and children who use water from the boreholes are at serious risk from exposure to health hazards associated with exposure to the above metals in the boreholes in Dumasi.

[15] explains that selenium deficiency is suspected to be a factor in the etiology of esophageal cancer in the Linxian and Cixian regions of the People's Republic of China. Vitamin trials in the Linxian area indicate that combined supplementation with $\beta$-carotene, vitamin $\mathrm{E}$ and Se reduces the mortality rate. He further explains that in order to further evaluate the role of Se, the distribution of total Se in cultivated top-soils, grain, human hair and drinking water is studied in 15 villages in the Cixian area, People's Republic of China which had one of the highest mortality rates from esophageal cancer in the world in the 1980-1990s. His study demonstrates that total Se concentrations in drinking water, soil, grain and hair increase from the low esophageal cancer area to the high cancer area, contrary to the expected trend.

\section{Methodology}

\subsection{Study Area}

This study area was chosen due to its high population density and the fact that it lies where the soils are drained, shallow, reddish brown and viscous, having developed from older basic igneous rock, particularly basic tuffs, basalts and phonolites. These types of soils are volcanic in nature and may contain trace elements, which is the subject of this study. The study area (Figure 1) covers the whole of Huruma estate, in Eldoret Municipality.

Huruma is one of the estates in Eldoret Municipality with the highest population, while pioneer and Elgon View have the lowest population [16]. The rapid population growth in the estate has led to shortage of housing, health facilities, water, poor sewage disposal and general degradation of environmental quality. This has in turn strained the Eldoret Municipality to provide these services [16].

The industries found near or around this estate include the Kenya Pipeline and the Rai Plywood. See Figure 2 below.

\subsection{Sapling Procedures}

The borehole sampling stations were systematically se-

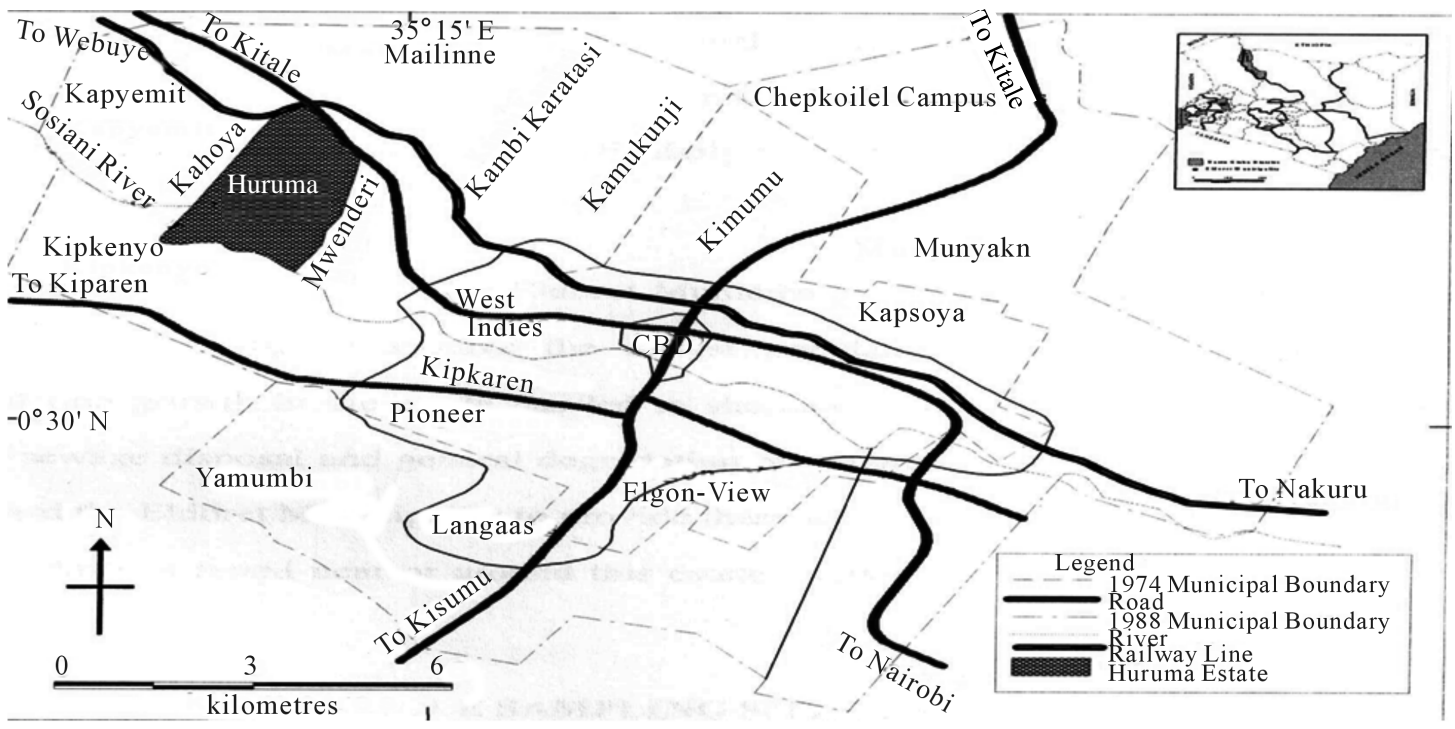

Figure 1. A Map of Eldoret Municipality (in Uasin-Gishu District) showing the study area (Huruma Estate). Source: Department of Geography Moi University. 


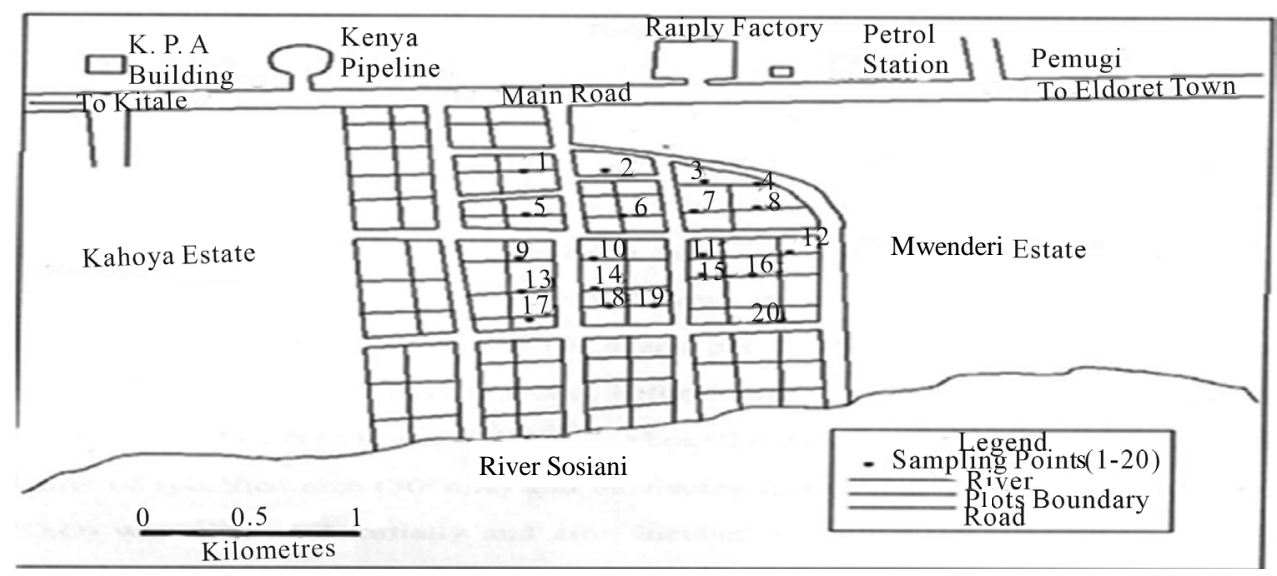

Figure 2. Sketch of the study showing sampling stations and industries.

lected after every two plots. Domestic water sample were collected in duplicate using $500 \mathrm{ml}$ plastic containers, previously soaked overnight in a mixture of concentrated nitric and hydrochloric acids. The bottles were rinsed 3 times in distilled water and the sample respectively, 2 mls of concentrated HCL was added for preservation of trace metals [17]. When sampling boreholes, the water sample, was lifted using a water bucket only dedicated for sampling.

\subsection{Laboratory Methods}

The duplicate water samples was pre-concentrated by heating an aliquot of $100 \mathrm{ml}$ form each sample on a water bath at $85^{\circ} \mathrm{C}$ until the volume was reduced to $10 \mathrm{ml}$. the concentration was cooled and analyzed for $\mathrm{Cu}$, Se, and $\mathrm{Cr}$, using an atomic absorption spectrometer (AAS), Varian mode. The AAS was chosen because of its availability, high accuracy, and high precision and sufficiently low detection limits for most trace elements in the environment [18].

\subsection{Data Analysis and Data Presentation}

Statistical analysis was done using SPSS for mean, standard deviation, t-test and confidence interval limits. The statistical t-test was used to test for significance difference at $(\mathrm{p}=0.05)$. The graphs were drawn using the Microsoft Excel package.

\section{Results and Discussion}

The table (Table 1 ) below shows the Se, $\mathrm{Cr}$ and $\mathrm{Cu}$ variations in the stations 1 (station near Industries) to 20 (stations away from industries and near river Sosiani). The results indicate that soils on the inhabited areas (the upper areas near the factories) of Huruma Estate had slightly more trace elements than the lower side to the river.
The mean value of Selenium, Copper and Chromium are shown in Table 1 and Figure 3 and illustrates the levels of these compounds at different sampling points in Huruma estate.

The overall selenium mean value was $22.7 \mu \mathrm{g} / \mathrm{L}$ and selenium values varied from $35 \mu \mathrm{g} / \mathrm{L}$, at sampling point 1 to $16 \mu \mathrm{g} / \mathrm{L}$, at sampling point 13 and values increases again to $18 \mu \mathrm{g} / \mathrm{L}$ at sampling point 20 . There was a significant difference $(\mathrm{PV}=0.000)$ at $5 \%$ level significance in copper levels among the sampling points in this area. At 95\% confidence level, the copper concentration was $22.7 \pm 2.7 \mu \mathrm{g} / \mathrm{L}$. These variations could be due to agricultural activities from nearby farms and industries to the upper parts of the estate, as most selenium is used preparations of pharmaceuticals as a nutritional feed additive for poultry and livestock, and in pesticides formulations [19]. This research finding concurs with [20] who found out that selenium concentration values were below [21] recommendation. However, the water is still fit for human consumption as the selenium concentrations are far below the WHO recommended limits of $0.05 \mathrm{mg} / \mathrm{L}$.

The Copper concentration data shows that sampling point 1 had $307 \mu \mathrm{g} / \mathrm{L}$, and this rapidly to a high value of $1031 \mu \mathrm{g} / \mathrm{L}$ at sampling point 10 and the values started reducing again to a low level of $207 \mu \mathrm{g} / \mathrm{L}$. the mean level of copper concentrations along the sampling point was $563 \mu \mathrm{g} / \mathrm{L}$. there was a significant $(\mathrm{PV}=0.000)$ difference at $5 \%$ level of significance in copper levels along all the sampling points. At 95\% confidence level, the copper concentration was $562.75 \pm 0.7 \mu \mathrm{g} / \mathrm{L}$. This could be due to copper ions coming from rusting roofing sheets and water plumbing pipes from houses in estate. This is the most populated area in Huruma estate. [20] confirms these results, where he found out that copper concentration values were below $2.0 \mathrm{mg} / \mathrm{L}$ as recommended by [21]. However, the water is safe for drinking since the $\mathrm{Cu}$ levels are below the WHO recommenced limits for drinking water $(1.3-2.0 \mathrm{mg} / \mathrm{L})$. 


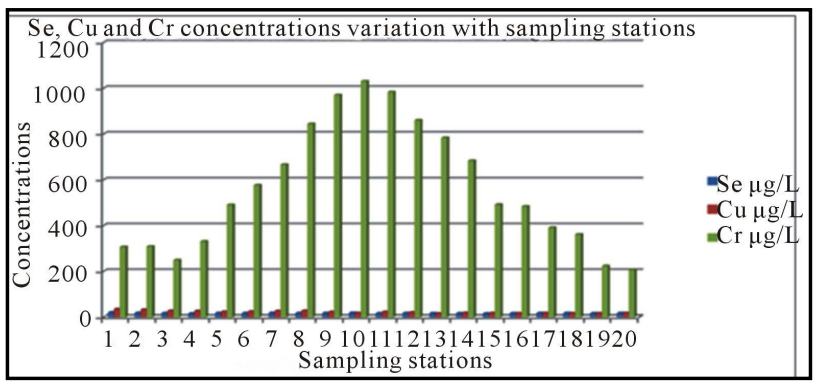

Figure 3. Se, Cu and $\mathrm{Cr}$ concentration variation with sampling stations.

Table 1. Variations of Se, $\mathrm{Cr}$ and $\mathrm{Cu}$ in all the sampling stations (1 - 20).

\begin{tabular}{cccccccc}
\hline Station & Se & $\mathrm{Cr}$ & $\mathrm{Cu}$ & Station & $\mathrm{Se}$ & $\mathrm{Cr}$ & $\mathrm{Cu}$ \\
\hline $\mathbf{1}$ & 21 & 307 & 35 & $\mathbf{1 1}$ & 17 & 984 & 23 \\
$\mathbf{2}$ & 19 & 309 & 33 & $\mathbf{1 2}$ & 18 & 861 & 21 \\
$\mathbf{3}$ & 18 & 250 & 28 & $\mathbf{1 3}$ & 17 & 784 & 16 \\
$\mathbf{4}$ & 16 & 331 & 27 & $\mathbf{1 4}$ & 17 & 684 & 19 \\
$\mathbf{5}$ & 18 & 491 & 24 & $\mathbf{1 5}$ & 16 & 492 & 18 \\
$\mathbf{6}$ & 18 & 577 & 25 & $\mathbf{1 6}$ & 17 & 484 & 17 \\
$\mathbf{7}$ & 19 & 667 & 27 & $\mathbf{1 7}$ & 18 & 392 & 18 \\
$\mathbf{8}$ & 18 & 845 & 28 & $\mathbf{1 8}$ & 18 & 362 & 17 \\
$\mathbf{9}$ & 18 & 971 & 23 & $\mathbf{1 9}$ & 17 & 224 & 17 \\
$\mathbf{1 0}$ & 19 & 1031 & 19 & $\mathbf{2 0}$ & 18 & 207 & 18 \\
\hline
\end{tabular}

Chromium values varied from $21 \mu \mathrm{g} / \mathrm{L}$, at sampling point 1 to $16 \mu \mathrm{g} / \mathrm{L}$, at sampling point 15 and $18 \mu \mathrm{g} / \mathrm{L}$ at sampling point 20. The overall mean was $17.85 \mu \mathrm{g} / \mathrm{L}$. At $95 \%$ confidence, chromium values were $17.9 \pm 0.6$. There was a significant difference $(\mathrm{PV}=0.000)$ at $5 \%$ level of significance in chromium levels among the sampling points and this due to the proximity of these points to the Raiply wood industry which manufactures paper products (among other products). However, the water quality was not affected as the chromium values were below the WHO recommended levels $(0.01 \mathrm{mg} / \mathrm{L})$ for the drinking water. This compares well with [20], where he found that chromium values were below WHO recommended levels.

\section{Conclusions and Recommendations}

\subsection{Conclusions}

Analysis of data indicated that the quality of water from borehole water in Huruma estate was acceptable. The volcanic soil around this area does not have any effect at all on the borehole water quality as earlier thought. The cases of cancer and cardiovascular diseases from this area are due to other causes, but not borehole water.
Variations of copper concentrations around the densely populated area of Huruma estate are affected by the human activities. Use of Copper pipes for water plumbing and corroded iron sheets has contributed to high levels of copper concentrations $(1031 \mu \mathrm{g} / \mathrm{L})$ as confirmed by the high levels of conductivity in the area at sampling points 10 (at $474 \mu \mathrm{g} / \mathrm{L}$ ). These levels are however, lower than the recommended WHO limits for drinking water. Mean selenium levels $(22.65 \mu \mathrm{g} / \mathrm{L})$ and chromium levels $(17.9 \mu \mathrm{g} / \mathrm{L})$ are still very low as compared to WHO limits for drinking water. Therefore, water from Huruma borehole will not cause cardiovascular and cancer diseases.

\subsection{Recommendations}

The government through the municipal council of Eldoret should give extensive health education on construction of borehole and use of borehole water to the Huruma residents. The municipal council should assist the Huruma residents in the construction of pit latrines to minimize borehole water contamination in the future. All the industrial waste effluents should be regularly analyzed and carefully monitored to ensure that no harmful discharges get into the soil.

The community should make efforts to have clean water by boiling water from their boreholes and rehabilitating their boreholes. They should also make efforts to ensure that they do not pollute borehole water supplies by discharging harmful wastes. The borehole water should only be used for cleaning and washing purposes if other water sources (tap water etc.) are reliable and pure enough for cooking and drinking.

\section{Acknowledgement}

I wish to thank the following for their advice and encouragement throughout the research project period. Dr. Augustine Afullo, Lecturer Kenyatta University, for his encouragement and advice during the research period. Mr. P. K. Maritim, Chief Technician and Mr. Rocky Mndumu Lewela, Senior Technician department of Environmental Biology and Health, School of Environmental Studies, Moi University for assisting me with trace elements analysis for my water samples.

\section{REFERENCES}

[1] W. Stumm and J. J. Morgan, “Aquatic Chemistry,” 2nd Edition, John Willey and Son, New York, 1991.

[2] R. T. Flint and J. B Skinner, "Physical Geology," 2nd Ed., John Wiley and Sons. New York, 1997, p. 11.

[3] H. T. Schacklette, H. I. Sauerand and A. T. Miesch, "Distribution of Trace Elements in the Occurrence of Heart Diseases in Georgia," Geological Society of America 
Bulletin, Vol. 83, No. 4, 1972, pp. 1077-1088. http://dx.doi.org/10.1130/0016-7606(1972)83[1077:DOT EIT]2.0.CO;2

[4] H. Ojiambo, "Hypertension in Kenya," Sunday Nation, Vol. 2210, 1996, p.16.

[5] J. Wakhisi, N. Patel, N. Buziba and J. Rotich, "Esophageal Cancer in North Rift Valley of Western Kenya," Makerere University, Kampala, 2006.

[6] WHO, "Chromium. International Programme on Chemical Safety,” Environmental Criteria, Geneva, 1988, p. 196.

[7] J. M. Borgono, P. Vicent, H. Venturino and A. Infante, "Arsenic in the Drinking Water of the City of Antofagasta: Epidemiological and Clinical Study before and after the Installation of the Treatment Plant," Environmental Health Perspective, Vol. 19, 1977, pp. 103-105.

[8] IPCS, “The Environmental Health criteria 200," WHO, Geneva, 1998.

[9] M. N. I Barclay, A. MacPherson and J. Dixon, "Selenium Content of a Range of Ukfood," Journal of Food Composition and Analysis, Vol. 8, No. 4, 1995, pp. 307-318. http://dx.doi.org/10.1006/jfca.1995.1025

[10] 2007. www.atsdr.cdc.gov/

[11] D. Wilson, “The Lead Scandal,” Heinemann Educational Books, London, 1983, pp. 17-19.

[12] A. Tucker, “The Toxic Metals,” Earth Island Ltd., London, 1972, pp. 15-181.

[13] K. B. Pelig-Ba, "Trace Elements in Ground Water from Some Crystalline Rocks in the Upper Regions of Ghana," Journal of Water, Air and Soil Pollution, Vol. 103, No.
1-4, 1998, pp. 71-89.

[14] S. Obiri, "Determination of Heavy Metals in Water Boreholes in Dumasi in the WASSA District of Western Region of the Republic of Ghana," Journal of Environmental Monitoring and Assessment, Vol. 130, No. 1-3, 2007, pp. 455-463.

[15] J. D. Appleton, O. Zhang, K. A. Green, G. Zhang, X. Liu and J. X. li, "Selenium in Soils, Grains, Human Hair and Drinking Water in Relation to Esophageal Cancer in the CIXIAN Area, Hebei Province People's Republic of China,” Applied Geochemistry, Vol. 21, No. 4, 2006, pp. 684-700.

[16] C. O. Ombura, “Towards an Environmental Planning Approach in Urban, Industrial Setting and Operations in Kenya, Faculty of Environmental Sciences,” PhD Thesis, University of Amsterdam, Amsterdam, 1997.

[17] E. Upor, Photometric Methods in Inorganic Race Analysis in Wilson and Wilson's, Comprehensive Analytical Chemistry, Vol. xx, 1985, pp. 30-137.

[18] R. J. Reynolds, K. Aldons and K. C. Thompson, “Atomic Absorption Spectroscopy,” Charles Griffin and Co. Ltd., London, 1970, pp. 78-115.

[19] Agency for Toxic Substances and Disease Registry (ATSDR), "Frequent Answers and Questions about Selenium," USA Department of Health and Human Services, Atlanta, 2003.

[20] B. K. Kortatsi, “Ground Water Quality in the Wassa West District of the Western Region of Ghana," CSIR, Water Research Institute, Accra Ghana, 2007.

[21] WHO, “Guidelines for Drinking-Water Quality,” 2nd Edition, WHO, Geneva, 1993. 